\title{
SOBRE UM PROCESSO CRIME DE ESTUPRO DE 1924: EDIÇÕES FILOLÓGICAS E ESTUDO GRAFEMÁTICO
}

\author{
$\underline{\text { Eliene Pinto de Oliveira }}^{1}$; Josenilce Rodrigues de Oliveira Barreto ${ }^{2}$ \\ 1. Bolsista PEVIC, Graduanda em Letras Vernáculas, Universidade Estadual de Feira de Santana, e-mail: \\ eliene.oliveira2@outlook.com \\ 2. Orientador, Departamento de Letras e Artes, Universidade Estadual de Feira de Santana, e-mail: \\ nilce11.barreto@gmail.com
}

\begin{abstract}
PALAVRAS-CHAVE: Filologia; Edições fac-similar e semidiplomática; Estudo Grafemático.
\end{abstract}

\section{INTRODUÇÃO}

Sabendo que a edição de textos é uma das atividades mais antigas da Filologia, este trabalho teve por objetivo realizar a edição fac-similar e semidiplomática de um Processo Crime de Estupro datado do ano de 1924, bem como o estudo grafemático das palavras que mudaram ao longo do tempo.

O termo Filologia vem do grego e significa amor pelo saber, pelo conhecimento, ou seja, o labor filológico consiste em estudar rigorosamente os textos, que são de grande importância para estudiosos de diversas áreas de pesquisa, os quais ampliam os seus conhecimentos acerca de determinado assunto. Segundo Santos (2006 p.79), "A filologia, em sentido amplo, estuda a língua, a literatura e a cultura representadas através de documentos e textos legados por uma determinada civilização [...]". Diante disso, vemos que o trabalho filológico contribui para conhecermos a cultura e a identidade de um povo, através da sua escrita.

Partindo do pressuposto de que o labor filológico consiste na restituição e conservação de textos produzidos em épocas pretéritas, buscou-se fazer a edição filológica de um documento da área crime, pertencente ao Fórum Desembargador Filinto Bastos, que se encontra no Centro de Documentação e Pesquisa (CEDOC), localizado na Universidade Estadual de Feira de Santana, com o intuito de preservar e tornar acessível o conteúdo do mesmo.

O documento estudado é um Processo Crime de Estupro de 1924, ocorrido na cidade de Feira de Santana, tendo como vítima uma menor de apenas treze anos de idade de nome Maria Arlinda Pedreira Ribeiro e como acusado, de ter praticado o ato sexual, Raul Barbosa de Almeida.

A escolha desse documento adveio por se tratar de um texto que possui necessidade de edição e preservação de seu conteúdo, o que contribui para os estudos na área da Filologia, principalmente por se tratar de um documento que já está bastante danificado pela ação do tempo, o que pode ocasionar a perda de suas informações.

\section{METODOLOGIA}

A metodologia utilizada na elaboração deste trabalho parte dos estudos de Queiroz (2007) e de Barreto (2014), nos quais há critérios que foram adotados nas edições de alguns manuscritos. Assim, na descrição do documento, foram observadas algumas características como, por exemplo, o número de colunas e de linhas, o tipo de escrita e papel, o número de 
abreviaturas, entre outras. Já para a transcrição do documento, foram utilizados os seguintes critérios, que serviram de suporte para a edição semidiplomática:

Respeitar fidedignamente o texto: grafia, linhas, fólios, etc.

Fazer remissão ao número do fólio no ângulo superior direito;

Numerar o texto linha por linha, constando a numeração de cinco em cinco;

Separar as palavras unidas e unir as separadas;

Desdobrar as abreviaturas usando itálico;

Utilizar colchetes para as interpolações: [ ];

Indicar as rasuras, acréscimos e supressões através dos seguintes operadores:

$((\dagger))$ rasura ilegível;

$[\dagger]$ escrito não identificado;

(...) leitura impossível por dano no suporte;

/ / leitura conjecturada;

<> supressão;

( ) rasura ou mancha

[ ] acréscimo

Após a edição do documento, foi realizado um estudo sistematizado da variação grafemática presente no corpus, para o qual uma amostra será apresentada a seguir.

\section{RESULTADOS E DISCUSSÃO}

A partir da edição filológica do Processo Crime de Estupro de Maria Arlinda Pedreira Ribeiro, de 1924, pudemos constatar qual a ortografia era utilizada na época em que o documento foi lavrado. Além disso, as edições fac-similar e semidiplomática tornam as informações desse documento acessíveis a pesquisadores de diversas áreas do conhecimento.

Assim, após o tratamento filológico dado ao documento, levantamos os aspectos codicológicos do suporte material, no qual foi verificado que o mesmo está bastante danificado, carecendo de uma restauração, bem como identificamos o tipo de escrita e de papel, e a presença de carimbo, como se vê a seguir.

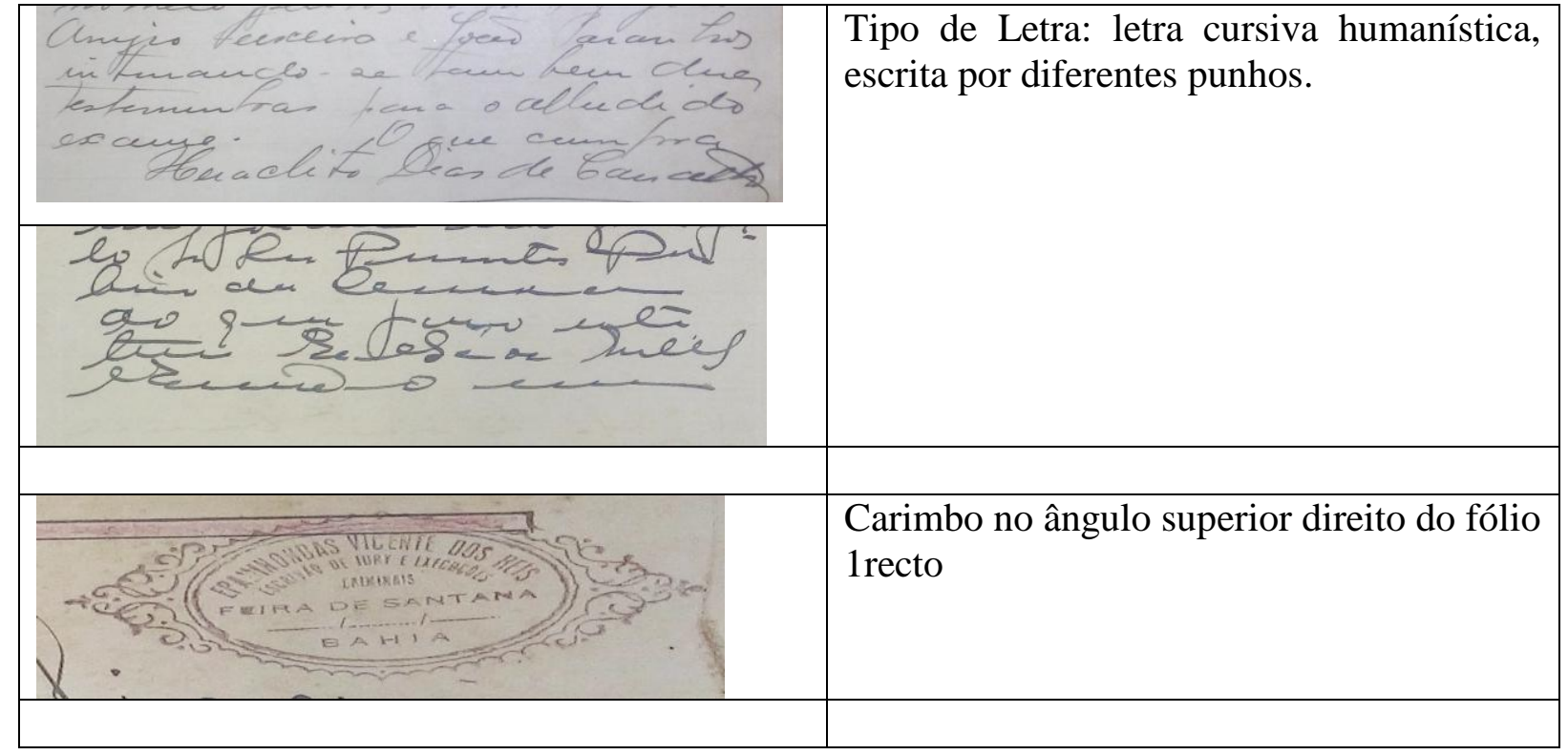




\begin{tabular}{|c|c|}
\hline 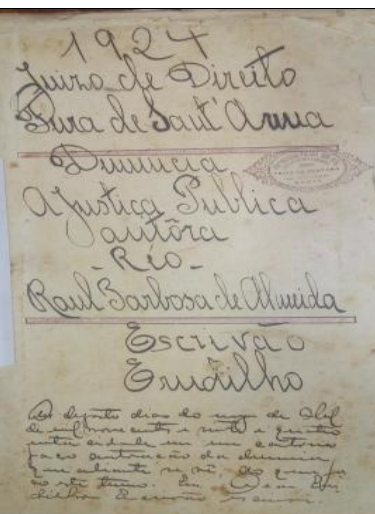 & $\begin{array}{l}\text { Documento escrito em papel almaço, } \\
\text { escrito no recto e verso contendo um total } \\
\text { de } 42 \text { fólios. }\end{array}$ \\
\hline
\end{tabular}

Figura 1: Edição fac-similar e semidiplomática do fólio 2r do Processo Crime de Estupro de Maria Arlinda Pedreira Ribeiro, de 1924.

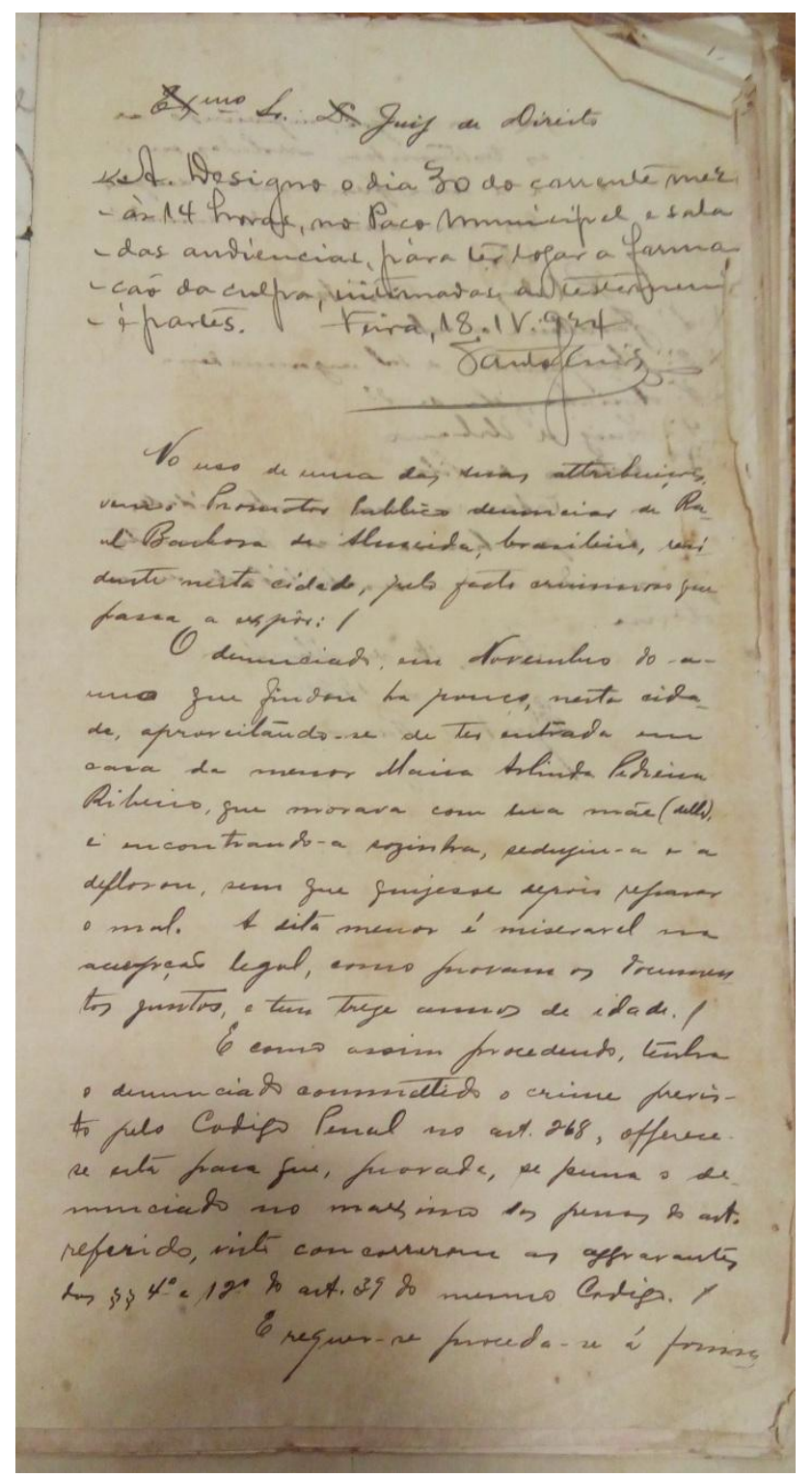

Excellentissimo Senhor Doutor Juiz de Direito

< Autora Designo o dia 30 do corrente mez, - às 14 horas, no Paço Municipal e sala

5 - das audiencias, para ter logar a forma- ção da culpa, intimadas as testemunhas - e partes. Feira, 18. IV. 924

[Assinatura]

10

No uso de uma das suas attribuições, vem o Promotor Publico denunciar a Raul Barbosa de Almeida, brasileiro, residente nesta cidade, pelo facto criminoso que 15 passa a expôr: /

O denunciado, em Novembro do anno que findou ha pouco, nesta cidade, aproveitando-se de ter entrada em casa da menor Maria Arlinda Pedreira

20 Ribeiro, que morava com sua mãe (delle), e encontrando-a sozinha, seduziu-a e a deflorou, sem que quizesse depois reparar o mal. A dita menor é miseravel na accepção legal, como provam os documen tos juntos, e tem treze annos de idade./

E como assim procedendo, tenha o denunciado commettido o crime previsto pelo Codigo Penal no artigo 268, offerecese esta para que, provada, se puna o de-

30 nunciado no maximo das penas do artigo referido, visto concorrerem os aggravantes dos $\S \S 4^{\circ}$ e $12^{\circ}$ do artigo 39 do mesmo Codigo./

$\mathrm{E}$ requer-se proceda-se á forma- 


\begin{tabular}{|c|c|c|}
\hline \multicolumn{2}{|c|}{ ANÁLISE DA VARIAÇÃO GRAFEMÁTICA DE ALGUMAS PALAVRAS } \\
CONSTANTES NO DOCUMENTO \\
\hline $\begin{array}{c}\text { GRAFIA CONSTANTE NO } \\
\text { DOCUMENTO DE 1924 }\end{array}$ & GRAFIA ATUAL (2017) & $\begin{array}{c}\text { ANÁLISE GRAFEMÁTICA } \\
(1924 \rightarrow \text { 2017) }\end{array}$ \\
\hline Sant'Anna & Santana & Dissimilação do nn > n \\
\hline Mez & Mês & Nasalização do z > s \\
\hline Attribuições & Atribuições & Dissimilação do tt > t \\
\hline Facto & Fato & Síncope do c \\
\hline Quizesse & Quisesse & Assimilação do z > s \\
\hline
\end{tabular}

\section{CONSIDERAÇÕES FINAIS}

A partir das edições filológicas e do estudo grafemático do documento pode-se contribuir para os estudos filológicos e linguísticos no que concerne ao conhecimento da ortografia da Língua Portuguesa do século XX. Logo, este tipo de estudo é de extrema importância para pesquisadores de diversas áreas do conhecimento, como afirma Queiroz (2006, p. 144) na seguinte passagem:

Os documentos históricos representam o patrimônio cultural, portanto são objeto de interesse de diversos pesquisadores nas mais variadas áreas do conhecimento humano: História, Filologia, Paleografia, Epigrafia, Diplomática, Linguística, Literatura, Direito, Teologia, dentre outras ciências. Nesse sentido, faz-se de grande relevância a sua preservação e conservação.

Desse modo, vemos que as edições fac-similar e semidiplomática são fundamentais para a preservação e conservação dos textos produzidos em épocas pretéritas, pois a partir daquelas podemos fazer o estudo ortográfico da Língua Portuguesa constante em documentos feirenses, lavrados no início do século XX.

\section{REFERÊNCIAS}

BARRETO, Josenilce Rodrigues de Oliveira. Pelos caminhos da separação: edição semidiplomática e estudo do vocabulário de uma "acção ordinaria de desquite" do início do século XX. 2014. 369f. Dissertação (Mestrado em Estudos Linguísticos) UniversidadeEstadual de Feira de Santana, Feira de Santana, 2014.

QUEIROZ, Rita de Cássia Ribeiro de. Introdução metodológica. In: . (Org.). Documentos do acervo de Monsenhor Galvão: edição semidiplomática. Feira de Santana: Universidade Estadual de Feira de Santana, 2007. p. 23-34.

Para que editar? A filologia a serviço da preservação da memória baiana. In:

SANTOS, Rosa Borges dos; TEIXEIRA, Maria da Conceição Reis (Org.). Diferentes perspectivas dos estudos filológicos. Salvador: Quarteto, 2006. p. 141- 150.

SANTOS, Rosa Borges dos. A filologia textual e a gramática estilística dos textos. In: QUEIROZ, Rita de Cássia de Ribeiro; SANTOS, Rosa Borges dos; TEIXEIRA, Maria da Conceição Reis (Org.). Diferentes perspectivas dos estudos filológicos. Salvador: Quarteto, 2006. p.79- 86. 